\title{
Novos aspectos da função social da propriedade
}

rdai.com.br/ojs/index.php/rdai/article/view/161

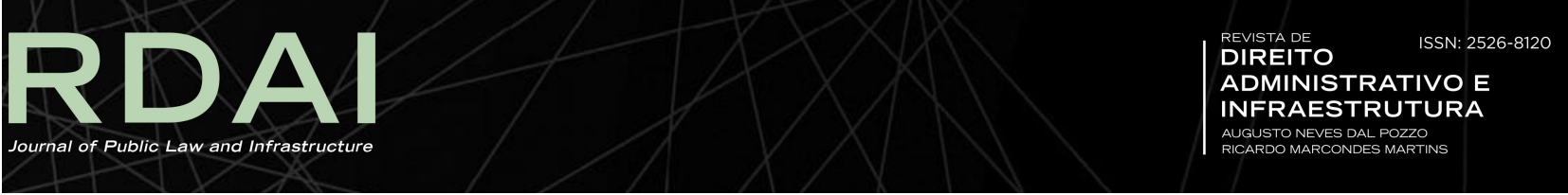

Celso Antônio Bandeira de Mello Pontifícia Universidade Católica de São Paulo (São Paulo, São Paulo, Brasil)

DOI: https://doi.org/10.48143/rdai/o8.cabm

Palavras-chave: direito de propriedade, Direito Público, Direito Privado

\section{Resumo}

1. O direito de propriedade - ou seja, o reconhecimento que a organização da Sociedade (Estado) dispensa aos poderes de alguém sobre coisas - encarta-se, ao nosso ver, no Direito Público e não no Direito Privado.1 É evidente que tal Direito comporta relações tanto de Direito Público quanto de Direito Privado. Entretanto, o direito de propriedade, como aliás sempre sustentou o prof. Oswaldo Aranha Bandeira de Mello é, essencialmente, um direito configurado no Direito Público e - desde logo - no Direito Constitucional

Com efeito, basta ver que dependendo do tratamento que for dispensado ao direito de propriedade um Estado será socialista ou capitalista, com todas as implicações jurídicas daí decorrentes. Trata-se, portanto, de um direito nodular à caracterização políticosocial do Estado e, por isso, de todo o quadro jurídico da sociedade; logo um Direito Público, por excelência.

De resto, ao falar-se em função social da propriedade está, ipso facto, fazendo referência à caracterização que o Direito Público lhe irroga. É o Direito Constitucional quem outorga esta fisionomia à propriedade.

2. Ninguém ignora que, de há muito, a propriedade e, pois, os poderes que se lhe consideram correlatos vêm sofrendo progressivo assujeitamento às conveniências sociais. Com isto, por óbvio, os proprietários passam a sofrer constrições cada vez maiores no uso, gozo e disposição dos bens que lhes pertencem.

Não se trata, propriamente, de restrições ou limitações ao "direito de propriedade", mas de restrições ou limitações à propriedade. Deveres - bem disse Renato Alessi - não são de confundir propriedade (ou liberdade) com direito de propriedade (ou direito de liberdade).

O direito de propriedade é a expressão juridicamente reconhecida à propriedade. É o perfil jurídico da propriedade. É a propriedade, tal como configurada em dada 
ordenação normativa. É, em suma, a dimensão ou o âmbito de expressão legítima da propriedade: aquilo que o direito considera como tal. Donde, as limitações ou sujeições de podres do proprietário impostas por um sistema normativo não se constituem em limitações de direitos pois não comprimem nem deprimem o direito de propriedade, mas, pelo contrário, consistem na própria definição desde direito, compõem seu delineamento e, desde modo, lhe desenham os contornos. Na Constituição - e nas leis que lhe estejam conformadas - reside o traçado da compostura daquilo que chamamos de direito de propriedade em tal ou qual país, na época tal ou qual.

3. Pois bem, se é fato que desde períodos recuados têm havido expressivas manifestações de que a propriedade deve ajustar-se a conveniências sociais - e valem como exemplo as velhas disposições urbanísticas para as colônias hispano-americanas ou o instituto do comisso nas concessões de sesmarias e cartas de data, no BrasilColônia - ninguém contestará que se está a falar de fenômeno bem mais recente, animado de características perfeitamente específicas, quando nos dias atuas se faz alusão à função social da propriedade. Sem embargo, esta temática já está vivamente posta em causa, pelo menos, desde o começo do século.

É memorável a série de conferências proferidas, por Léon Duguit, em 1911, na cidade de Buenos Aires e que foram convertidas em livro, publicado na França em 1912, nas quais este alumiado jurista expunha a concepção de que o proprietário, ao invés de titular de um direito subjetivo, era apenas o detentor da riqueza, de certo modo na condição de gestor de um bem socialmente útil, pois a propriedade devia ser concebida, em si mesma, como uma função social - não como um direito ajustável a uma função social.

A Constituição de Weimar, de 1919, dispunham, em seu art. 153, que a propriedade acarreta obrigações para seu titular e que o direito de propriedade acarreta obrigações para seu titular e que o direito de propriedade deve ser exercido no interesse social.

4. Vejamos qual a evolução deste tema nos dispositivos dos vários Textos Constitucionais brasileiros. As Constituições de 1824 e 1891, respectivamente em seus arts. 179, 22 e 72, § 17, simplesmente declaravam garantido o direito de propriedade em toda sua plenitude.

É com a Constituição de 1934 que, pela primeira vez, em Lei Magna brasileira, se fez expressa referência as relações entre propriedade e função social. No art. 113, 17, estatui-se ser garantido o direito de propriedade que não poderá ser exercido contra o interesse social ou coletivo. Nota-se que, embora não afiliando a propriedade ao cumprimento de um interesse social, opõe-se a ela uma barreira: a vedação de que o correspondente direito seja utilizado em desacordo com o interesse social ou coletivo.

A Carta de 1937 é silente quanto a este tópico, o qual irá ressurgir com a Constituição de 1946. Sobre estatuir que a garantia do direito de propriedade não o resguarda contra a desapropriação por interesse social - além dos casos de necessidade ou utilidade pública - consoante rezava seu art. 141, § 16, explicitamente dispôs, no art. 147, que "o uso da propriedade será condicionado ao bem estar social. A lei poderá com 
observância do disposto no art. 146, § 16, promover a justa distribuição da propriedade, com igual oportunidade para todos". Sem dúvida alguma, este preceptivo é um marco jurídico. Com efeito, não apenas se prevê a desapropriação por interesse social, mas se aponta, no aludido art. 147, para um rumo social da propriedade, ao ser prefigurada legislação que lhe assegure justa distribuição, buscando mais que a tradicional igualdade perante a lei, igualdade perante a oportunidade de acesso à propriedade.

5. Nas Cartas de 1967 e 1969, conquanto inexistia este tipo de alusão, ao nosso ver muito prezável, há, contudo, outro avanço na linguagem normativa. De fora parte a reiteração da expropriabilidade de bens por interesse social - tal como referido na Constituição de 1946 - sobre vir suposta uma modalidade de desapropriação específica para imóveis rurais, em certas condições, com pagamento em títulos da dívida pública, resgatáveis em parcelas anuais e sucessivas ao longo de 20 anos (art. 157, §§ da Carta de 1967 e 161 e $\S \S$ da Carta de 1969), ambas proclamam explicitamente a "função social da propriedade".

Fazem-no em termos que podem ser considerados enfáticos, pois a Carta de 1967, no art. 157 e a de 1969, no art. 160, declaram ser finalidade da ordem social realizar entre outros princípios arrolados, o da "função social propriedade" (item III dos citados versículos). Já agora, portanto, não se trata apenas de coibir o uso antissocial da propriedade, mas o de fazer com que cumpra tal função, já que esta passa a ser um bem jurídico conaturalmente definido, a nível constitucional, como teleologicamente orientado para este destino.

6. Surge aqui o primeiro dentre os quatro tópicos que, nesta exposição, nos propomos a aflorar com base no direito posto, a saber: 1) a propriedade é uma função social ou é direito que deve cumprir uma função social? 2) em nosso sistema podem ser distinguidos como direitos autônomos, o direito de propriedade e o direito de usar dela? 3) dever-se-á entender por função social apenas o destino economicamente útil do bem ou com tal locução quer-se significar, demais disso, a possibilidade de operar um projeto de "justiça social", substanciável - à moda do que referia a Constituição de 1946 - com propósito de favorecer a ampliação do acesso de todos à propriedade, gerando iguais oportunidades aos indivíduos ou concorrendo para ensejá-las? 4) cabem apenas limitações à propriedade, isto é, vedações ao uso insatisfatório dela à luz da função social, ou podem ser impostas injunções positivas para exigir que se engaje nesta linha de interesse?

7. Consideremos o primeiro tópico. Estamos em crer que, ao lume do direito positivo constitucional, a propriedade ainda está claramente configurada como um direito que deve cumprir uma função social e não como sendo pura e simplesmente uma função social, isto é, bem protegido tão só na medida em que a realiza.

Deveras, a entender-se que o protegido é a propriedade função-social, ter-se-ia, consequentemente, que concluir ausente a proteção jurídica a ou às propriedades que não estivessem cumprindo função social. Estas, pois, deveriam ser suscetíveis de serem 
perdidas, sem qualquer indenização, toda e cada vez que fosse demonstrável seu desajuste à função social que deveriam preencher.

Ora, o art. 161 da Carta do País, prevê desapropriação, mediante indenização, embora através dos aludidos títulos da dívida pública, para os imóveis rurais incursos nesta modalidade expropriatória. Pois bem, quais são eles? São - na dicção deste preceito os que "contrariem o acima disposto", isto é, o disposto no art. 16o, o qual, justamente, conforme se disse, consagra a "função social da propriedade" (entre outros interesses a que a ordem econômico-social deve servir). Ergo, existe proteção também para a propriedade que contrarie a função social, conquanto tal proteção seja menos completa, pois, neste caso, a indenização devida não se apura segundo o "justo" perquirível ao lume do valor efetivo do imóvel, mas segundo os critérios que a lei estabelecer e far-se-á “em títulos especiais da dívida pública, resgatáveis no prazo de vinte anos, em parcelas anuais e sucessivas...”, tudo como dispõe o referido art. 161.

8. Diga-se de passagem que o Supremo Tribunal Federal, adversando às escâncaras a letra e o espírito do regramento constitucional, vem entendendo que, mesmo nestes casos, há de buscar-se um justo valor indenizatório aferível pelo valor de mercado. Nisto, o STF rejeitou a linguagem clara do art. 161 que remeteu o justo ao critério legal (“justa indenização segundo os critérios que a lei estabelecer”) sendo que existe lei regulando a forma de apurá-lo - o Dec.-lei 554, de 25.4.69 - como ignorou olimpicamente a ressalva do art. 153. § 22. É que este preceptivo, após estabelecer a justa indenização como regra para os casos de desapropriação, fez explícita ressalva ao disposto no art. 161.

9. De toda sorte - mesmo prescindindo da arbitrariedade interpretativa praticada pela Suprema Corte - é inegável que o art. 161 impede a intelecção de que a propriedade utilizada em descompasso com a função social carece de proteção jurídica. Donde, não ser acolhível o entendimento de que, em nosso direito, a propriedade é uma função, à falta do que assujeita-se, nos termos das leis existentes ou que se editem, às medidas conformadoras ou a eventual desapropriação.

10. O segundo tópico também não pode, ao nosso ver, ensejar resposta consentânea com as posições mais avançadas na matéria. É dizer: não cabe admitir, em face do direito brasileiro, a possibilidade de se considerar - como o fazer os direitos espanhol e italiano, por exemplo - que o direito de propriedade e o direito de usar da propriedade em sua manifestação edilícia, são direitos distintos, autônomos. Não é possível considerar que o direito de construir é uma “concessão" do Poder Público, por consistir em algo diverso do direito de propriedade.

Deveras, ao declarar que é garantido o direito de propriedade, o Texto Constitucional certamente assegurou algo mais que uma palavra oca, que um som vazio, que um semsentido. Donde, é forçoso reconhecer que existe um conteúdo mínimo significativo ao qual se reportou a Carta do País.

Se não fora assim, inexistiria garantia constitucional da propriedade, mas apenas - e 
eventualmente - garantia legal, pois as normas deste escalão atribuiriam (ou não) e na medida em que bem quisessem o sentido e a extensão do direito de propriedade. Não há como negar que à Lei assiste amplo espaço para delinear o direito de propriedade, mas, à toda evidência, haverá de existir um conteúdo mínimo que se tem por referido pela Carta Constitucional. O qual não pode ser desconhecido ou deprimido.

\section{Qual seria este conteúdo mínimo?}

Ao pronunciar-se o som "propriedade" todos entendem que está sendo feita alusão à possibilidade de usar, gozar e dispor de uma coisa. Donde, ter-se-á de entender que o Texto Constitucional, ao servir-se deste vocábulo, aludiu a sua significação corrente. Sendo as palavras meios de comunicação e havendo a Lei Maior se valido de uma palavra que possui um sentido usual, uma vez que não a redefiniu, forçosamente haverá se utilizado dela na acepção que se lhe atribuiu correntemente.

Logo, o direito de usar do bem e de nele edificar, assim como o direito de dispor, são expressões do direito de propriedade, dele inseparáveis, pois é o plexo destes poderes de uso, gozo e disposição que, em sua unidade, recebe o nome de direito de propriedade. Elididos estes podres, nada mais restaria. Daí a impossibilidade de considerar direitos autônomos, distinguíveis, o direito de propriedade e o direito de construir, de usar, de gozar ou de dispor do bem.

12. De outro lado, com dizer que a "função social da propriedade" é princípio basilar da ordem econômica e social, a Carta do País deixou explícito que a propriedade e que, portanto, todas as suas expressões naturais - o uso, o gozo e a disposição do bem - não só podem, mas devem, ser regulados de maneira tal qual se assujeitem às conveniências sociais e que se alinhem nesta destinação, de tal modo que a propriedade cumpra efetivamente uma função social. E aqui entramos em um tópico fundamental, a ser considerado como terceiro ponto que nos propusemos referir.

Afinal, que é função social da propriedade?

13. Perante a imposição constitucional de que a ordem econômica e social realize o princípio da "função social da propriedade", cabem, em tese, as seguintes distintas intelecções sobre o significado desta "função social" que lhe é exigida.

Numa primeira acepção, considerar-se-á que a "função social da propriedade" consiste em que esta deva cumprir um destino economicamente útil, produtivo, de maneira a satisfazer as necessidades sociais preenchíveis pela espécie tipológica (ou pelo menos não poderá ser utilizada de modo a contraditar estes interesses), cumprindo, dessarte, às completas, sua vocação natural, de molde a canalizar as potencialidades residentes no bem em proveito da coletividade (ou, pelo menos, não poderá ser utilizada de modo a adversá-las).

Em tal concepção do que seria a função social da propriedade, exalça-se a exigência de que o bem seja posto em aptidão para produzir sua utilidade específica, ou, quando menos, que seu uso não se faça em desacordo com a utilidade social. 
Nesta primeira acepção - distintamente de outro possível entendimento sobre função social da propriedade, sobre o qual se falará mais além - não se põem em pauta exigências de uma ordem social mais justa em relação aos economicamente hipossuficientes, não se coloca a temática de um maior equilíbrio ou nivelamento dos vários segmentos da sociedade; em uma palavra, não há preocupações com a chamada Justiça Distributiva. Função social da propriedade é tomada como necessidade de que o uso da propriedade responda a uma plena utilização, otimizando-se ou tendendo-se a otimizar os recursos disponíveis em mãos dos proprietários ou, então, impondo-se que as propriedades em geral não possam ser usadas, gozadas e suscetíveis de disposição, em contradita com estes mesmos propósitos de proveito coletivo.

14. É desta linha, por exemplo - para referir instituições vetustas - a previsão, nas concessões de sesmaria e cartas de data ao tempo do Brasil-Colônia, de que as terras não demarcadas e cultivas revertessem à Coroa (comisso), para serem redistribuídas a quem lhes desse destino produtivo, isto é, socialmente útil. Do mesmo modo, a Lei Imperial 601, 1850 e seu Regulamento, 1.318, de 1854 - normas que cumpriram função fundamental em matéria fundiária - prestigiaram ao máximo, nas revalidações de propriedade e legitimações de posse, a efetiva utilização da terra, vale dizer, sua preposição em atividade produtiva.

A legislação vigente sobre reforma agrária (Lei 4.504, de 30.11.64) também privilegia este aspecto - da aplicação produtiva da terra - pois exclui das desapropriações embasadas no arr. 161 da Carta do País as “empresas rurais”, isto é, os imóveis economicamente aproveitados de acordo com os padrões regularmente estabelecidos. Assim, ainda aqui o que prepondera é uma concepção de fundo social da propriedade ligada à atribuição de um destino útil a ela.

Advirta-se, entretanto, que o art. 161 comporta desapropriações por títulos em hipóteses muito mais amplas, posto que, conforme dantes se disse, tem incidência possível em quaisquer casos nos quais a propriedade territorial rural contrarie as diretrizes do art. 160, o qual, sobre referir a função social da propriedade, encampa ainda os princípios da "valorização do trabalho como condição da dignidade humana" (item II), "harmonia e solidariedade entre as categoriais sociais de produção" (item IV), "repressão do abuso do poder econômico, caracterizado pelo domínio dos mercados, eliminação da concorrência e aumento arbitrário dos lucros" (item V) e "expansão das oportunidades de emprego" (item VI).

15. É certo, contudo, que mesmo a perspectiva restrita sobre o alcance da expressão função social propriedade - vinculando-a tão só ao destino produtivo do bem - já permitiria adotar, caso se desejasse fazê-lo deveras, uma série de providencias aptas a conformá-la ao proveito coletivo. Assim, exempli gratia, a instituição de uma pesada e progressiva tributação sobre imóveis rurais e urbanos ociosos ou insatisfatoriamente utilizados, a proteção legal a posses produtivas sobre prédios rústicos inaproveitados 
por seus titulares ou sobre terrenos urbanos estocados para valorização e não edificados, seriam providências confortadas pela noção de função social da propriedade, mesmo que disto se tenha uma visão atreladas tão somente à sua aplicação útil.

É verdade, consoante observação feita anteriormente, que o sistema legal não pode negar proteção à propriedade alheiada de um destino socialmente útil, pena de transmudar a propriedade em mera função social, ao invés de reconhece-la como um direito que se deve ajustar tal função, mas sem dúvida pode agravar os que se recusam a tal submissão, estimulando-os, pois, a se vergarem ao intento constitucional.

16. À expressão "função social da propriedade" pode-se também atribuir outro conteúdo, vinculando a objetivos de Justiça Social; vale dizer, comprometido com o projeto de uma sociedade mais igualitária ou menos desequilibrada - como é o caso do Brasil - no qual o acesso à propriedade e o uso dela sejam orientados no sentido de proporcionar ampliação de oportunidades a todos os cidadãos independentemente da utilização produtiva que porventura já esteja tendo.

Nesta hipótese, seriam cabíveis providencias normativas que tomassem por norte estes objetivos, ensejando, e.g., desapropriações com o fito de promover o acesso à propriedade, rural ou urbana, dos sem-terra ou sem habitação, facultando disposições legais defensivas da melhoria das condições de vida dos hipossuficientes, como a participação dos empregados nos frutos, ou nos lucros de qualquer empreendimento promovido por pessoa jurídica ou física com o concurso de assalariados.

17. Parece fora de dúvida que a expressão "função social da propriedade" comporta não apenas o primeiro sentido, a que dantes se aludiu, mas também esta segunda acepção a que ora estamos reportando. Com efeito, se alguma hesitação pudesse existir tanto a isto, bastaria uma simples inspeção visual no art. 160 da Carta do País - antas vezes referido - para verificar-se que nele está explicitamente afirmado ser finalidade da ordem econômico e social realizar o desenvolvimento nacional e a justiça social. Ora bem, uma vez que estas finalidades hão de ser realizadas com base, entre outros princípios, no da "função social da propriedade" (item III), é óbvio que esta foi concebida tomando em conta objetivos de justiça social.

De passagem observa-se que seria equivocado supor que entre "desenvolvimento nacional" e justiça social" haja sido priorizado o primeiro, pelo fato de - na redação do art. 160 - ter sido mencionado antes. Como bem anotou Eros Grau, tal precedência é puramente redacional, não trazendo consigo outra implicação. Aliás, basta examinar os diversos itens do preceptivo em causa para ver que apontam sobretudo para o tópico da justiça social. Assim, o que se deverá depreender dele é que o "desenvolvimento nacional” terá de se realizar de modo obediente à justiça social, ou seja, concorrendo para realiza-la. Não é ela que se atrelará ao desenvolvimento. É o desenvolvimento que se atrelará a este projeto de justiça.

18. O último dentre os quatro tópicos incialmente referidos, põe em causa a questão de saber-se se, em nome da função social da propriedade, cabe tão só a edição de 
regras proibitivas que obstem o uso antissocial da propriedade ou se, demais disso, há a possibilidade de impor ao dominus, através de lei, comportamentos ativos que se alinhem na direção do proveito social.

Do quanto se disse até aqui já é possível inferir que consideramos exequível - revendo nisto anterior posicionamento sobre a matéria - também esta imposição legal de sujeições da propriedade a um compromisso positivo com a função social. Então, parece-nos cabível, por exemplo, a previsão de obrigações de construir, impostas ao proprietários de terrenos ociosos, ou a de coloca-los no mercado em prazo fixo, ou mesmo a de sujeitar-se a empreendimentos de remodelação urbana, à moda do que se estabelece no direito espanhol.

19. Sem embargo, cumpre ressalvar que a imposição de obrigações de fazer tem de aterse a limites muito cautelosos para não se transmudar em instrumento de perseguições pessoais ou políticas ou ainda em veículo de favorecimento de interesses de grupos. Além disso é preciso convir que tais providencias podem igualmente ser fonte de maiores desajustes sociais quando incidem sobre segmentos da população que inobstante dispondo de propriedades muitas vezes carecem de meios para lhe dar destinação mais produtiva.

Assim é que, inobstante nos pareçam compatíveis com o Texto Constitucional, para não se converterem em fórmulas que terminariam por desvirtuar a alvejada "função social da propriedade", hão de ser compostas com critérios de aturado precado, sem o que redundariam, elas mesmas, em disposições inconstitucionais, seja por atentarem contra as garantias do cidadão arroladas no art. 153 ou decorrentes do sistema (como refere o § 36 do mesmo artigo), seja por terminarem assumindo o vetor antagônico à justiça social. Assim, apenas um exame caso por caso autorizaria a concluir se as injunções positivas guardariam ou não afinidade com o regramento constitucional.

Feita essa necessária ressalva, convém esclarecer porque considerarmos aberta a possibilidade da lei impor a este propósito obrigações de agir, além das meras proibições coibitivas de uso antissocial da propriedade. É que, na Carta vigente, tal como na de 1967, não se fala apenas, como ocorria em 1946, em “condicionamento" da propriedade ao bem-estar social ou na proibição de seu exercício em contradita ao interesse social coletivo, como dizia a Constituição de 1934. Fala-se, muito claramente, que a "função social” da propriedade é princípio de toda ordem econômica e social. Logo, à propriedade atribui-se o caráter de um direito vocacionado a atender à finalidade do desenvolvimento econômico e da justiça social. Segue-se que o Estado pode pretender dos proprietários que concorram nesta direção - e não apenas que se abstenham de adversar esta diretriz (1986).

\section{Downloads}

Não há dados estatísticos.

\section{Biografia do Autor}


Celso Antônio Bandeira de Mello, Pontifícia Universidade Católica de São Paulo (São Paulo, São Paulo, Brasil)

Professor Emérito da Pontifícia Universidade Católica de São Paulo (PUC-SP).

\section{Referências}

Artigo originariamente publicado na Revista de Direito Público, São Paulo, ano XX, n. 84, p. 39-45, out.-dez. 1987.

MELLO, C. Novos aspectos da função social da propriedade. RDAI | Revista de Direito Administrativo e Infraestrutura, v. 3, n. 8, p. 409 - 418, 30 set. 2020. https://doi.org/10.48143/rdai/o8.cabm 


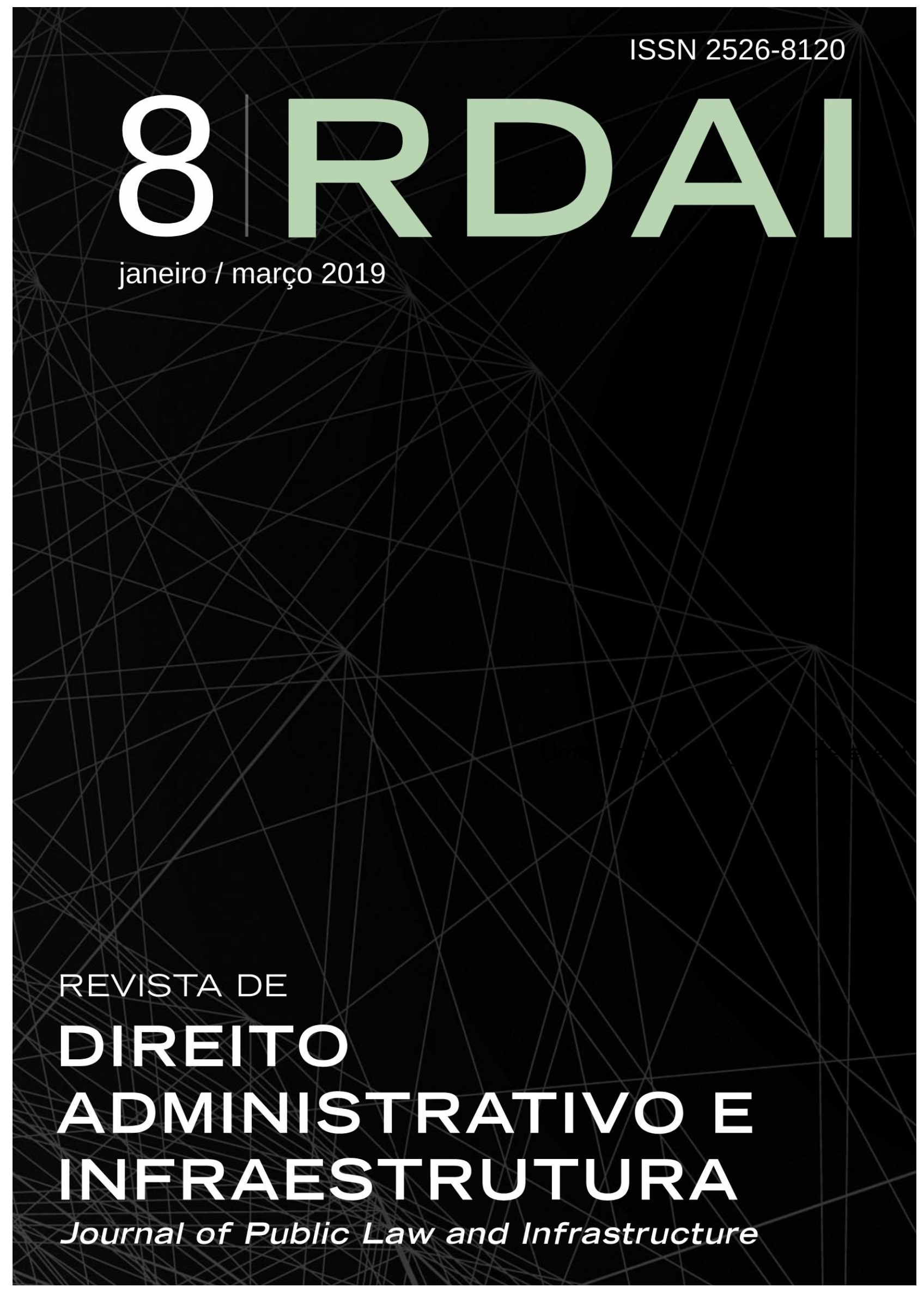

Publicado 
Edição

v. 3 n. $8(2019)$

Seção

Artigos

A submissão e a publicação de artigos são gratuitos; avaliados por pares; o periódico utiliza o CrossCheck (antiplágio) e cumpre com o Guia dos Editores da COPE - Committee on Publication Ethics, além das recomendações Elsevier e SciELO. Confira as Regras para a submissão e avaliação da RDAI. 